\title{
CONDIÇÃO CORPORAL E CARACTERÍSTICAS DE CARCAÇA DE VACAS DE DESCARTE NA REGIÃO DE LAVRAS-MG ${ }^{1}$
}

\author{
Body condition and carcass characteristics of culling cows in the region of Lavras-MG \\ Ivalda de Albuquerque Lima ${ }^{2}$, Carlos Alberto Pereira de Rezende ${ }^{3}$, \\ Paulo César de Aguiar Paiva ${ }^{3}$, Ivo Francisco de Andrade ${ }^{3}$, Joel Augusto Muniz
}

\begin{abstract}
RESUMO
Em inúmeras pesquisas, tem sido verificada a inferioridade da carcaça e da carne de vacas, principalmente de vacas de descarte que são levadas ao abate muito velhas e/ou com acabamento inadequado. Com este trabalho, teve-se como objetivos estabelecer entre as vacas abatidas no município de Lavras-MG a condição corporal mais freqüente durante o período de março a julho e avaliar a relação existente entre condição corporal e rendimento de carcaça e de alguns cortes do traseiro. O levantamento foi conduzido no matadouro municipal de Lavras-MG e dividido em duas fases assim compreendidas: Fase 1 ( $1^{\circ}$ a 31 de março de 2001), na qual se determinou que $53,41 \%$ do total de animais abatidos no período foram fêmeas e que os escores de condições corporais (ECC) mais frequientes entre elas foram 3, 4 e 5. Na fase 2 (15 abril a 15 de julho de 2001), foram utilizadas 140 fêmeas, 42 vacas da CC 3, 59 fêmeas da CC 4 e 39 da CC 5. Em cada escore, as vacas foram classificadas em três grupos genéticos: azebuadas, holandesadas e mestiças. No matadouro, antes do abate, as vacas foram pesadas, classificadas quanto à condição corporal e grupo genético e fotografadas para posterior classificação por outros avaliadores. Os parâmetros avaliados foram: rendimento de carcaça quente (RCQ), peso da gordura renal e pélvica, área de olho de lombo (AOL), espessura de gordura de cobertura (EGC) e pesos dos cortes (contrafilé, alcatra completa e filé mignon). O escore de condição corporal (ECC) teve influência sobre o RCQ, a EGC, o peso da gordura renal e pélvica e o peso da alcatra completa nos três grupos genéticos. Para a AOL e o peso do filé mignon, só foi observado efeito do ECC sobre as vacas azebuadas; o peso de contrafilé não foi afetado pelo ECC. As vacas azebuadas apresentaram maior RCQ e EGC; porém, a maior AOL foi observada entre as vacas holandesadas. A gordura renal e pélvica e o peso dos cortes (alcatra, contrafilé e filé mignon) não variaram entre os grupos genéticos. Pelos resultados obtidos, pode-se concluir que as vacas abatidas no período apresentaram baixa condição corporal e que essa influencia as características de rendimento na carcaça.
\end{abstract}

Termos para indexação: Carcaça, escore de condição corporal, vacas de descartes.

\begin{abstract}
A number of research works have shown the inferiority of the carcass and of the meat of cows mainly of cull cows which are led to slaughter very old and/ or with an unsuitable finishing. This work was aimed to establish among the cows slaughtered in the town of Lavras - Mg the most frequent body condition during the period of March to July and to evaluate the relationship existing between body condition and carcass yield and the yield of some cuts of the rear. The survey was conducted in the slaughterhouse of the town of Lavras - MG and divided into two phases, thus comprehended : phase 1 ( $1^{\text {st }}$ to $31^{\text {st }}$ of March 2001) determined that $53.41 \%$ of the total of animals slaughtered in the period were females and that the body condition scores (BCS) more frequent among them were 3,4 and 5 . In phase $2\left(15^{\text {th }}\right.$ April to $15^{\text {th }}$ July 2001) were utilized 140 females viz. 42 cows of BCS 3, 59 females of BCS 4 and 39 of BCS 5. In each sore the cows were ranked into three genetic groups: zebu- crossed, Holstein- crossed and crossbred. In the slaughterhouse before slaughter the cows were weighted classified as to body condition and genetic group and photographed for further classification by other referees. The evaluated parameters were: HCY, kidney and pelvic fat weight LEA, PFT and weight of the cuts (striploin, whole rump and tenderloin). The body condition score (BCS) influenced the HCW, PFT kidney and pelvic weight and the weight of the whole rump in the three genetic groups. For the LEA and weight of the tenderloin only the effect of the BCS on the zebu-crossed cows was found, striploin weight was not affected by the BCS. The zebu-crossed cows presented a greater HCY and PFT but the largest LEA was observed among the Holstein cows. The kidney and pelvic fat and the weights of the cuts (striploin, rump and tenderloin)
\end{abstract}

(Recebido para publicação em 8 de abril de 2002 e aprovado em 21 de agosto de 2003)

\footnotetext{
1. Parte de dissertação do primeiro autor apresentada à Universidade Federal de Lavras/UFLA, Caixa Postal 37 - 37200-000 - Lavras, MG, para obtenção do título de mestre.

2. M.Sc. Produção Animal - Professora da Escola Agrotécnica Federal de Vitória de Santo Antão, Rua José Vieira 3B, Centro - Pombos, PE.

3. Professores do Departamento de Zootecnia da UFLA.

4. Professor do Departamento de Ciências Exatas da UFLA.
} 
did not range among the genetic groups. From the results obtained, one can conclude that the cows slaughtered in the period presented poor body condition and that this influenced the carcass yield characteristics.

Index terms: Carcass, body condition score, culling cows.

\section{INTRODUÇÃO}

Nos sistemas de criação de bovinos, as fêmeas que deixam de interessar à reprodução, seja por seleção genética, seja por idade avançada ou problemas na produção, formam as vacas de descarte que, em geral, apresentam rendimento de carcaça inferior e carne com problemas de qualidade; nos países desenvolvidos, são utilizadas, principalmente, na produção de carne industrializada. No Brasil, são comercializadas basicamente no mercado interno. Por essas razões, os estabelecimentos de abate pagam um preço inferior ao produtor pela carcaça desses animais. Esses problemas que a cadeia produtiva de carne bovina enfrenta para padronizar o produto final e tornar-se mais competitiva são dificuldades observadas no Brasil e também em outros países, tanto que a indústria de carne dos E.U.A., em estudo realizado pela Universidade Estadual do Colorado, denominado National Non-Fed Beef Quality Audit (NNFBQA, 1994), verificou que cerca de 19\% de todos os bovinos abatidos no país são animais não-terminados em confinamento e que $75 \%$ desses são vacas. Entre os vários problemas apresentados por esses animais, destacam-se o mau estado nutricional, carcaças extremamente leves, com escores de musculosidade muito baixos. Portanto, é necessário que se estabeleçam mudanças no sistema produtivo de carne bovina, especificamente na categoria vacas de descarte, resultando em carcaças de qualidade superior e de maior aceitação no mercado.

Com o presente estudo, objetivou-se estabelecer, entre as vacas abatidas no município de Lavras - MG, a condição corporal (CC) mais frequiente durante o período de março a julho e avaliar a relação existente entre condição corporal e rendimento da carcaça e de alguns cortes do traseiro.

\section{MATERIAL E MÉTODOS}

Os dados foram coletados durante o período de $1^{\circ}$ de março a 15 de julho de 2001 em duas fases, assim compreendidas: FASE -1 : de $1^{\circ}$ a 31 de março de 2001 - durante esse período, determinou-se o número de fêmeas e machos abatidos e, entre as fêmeas, foi realizada a avaliação da condição corporal (CC), obedecendo ao critério adotado por Richards et al. (1986), que classificaram os animais por pontuação, numa escala de 1 a 9 . Essa avaliação teve por finalidade determinar as condições corporais mais freqüentes entre as fêmeas a- batidas no período. FASE -2: de 15 de abril a 15 de julho de 2001 - nesta fase, foram realizadas as coletas dos dados (variáveis estudadas), utilizando apenas as vacas que apresentavam escore de condição corporal compatíveis com aqueles determinados como mais freqüentes na primeira fase.

Para avaliação da área de olho de lombo (AOL) e espessura de gordura de cobertura (EGC), foram utilizadas apenas algumas vacas de cada grupo, de modo que houvesse representação tanto de vacas dos escores avaliados no estudo como também dos três grupos genéticos. O peso dos cortes do serrote foi feito com as vacas que pertenciam à Cooperativa Agrícola Alto Rio Grande Ltda para diminuir o erro experimental, já que o açougue pertencente à referida Cooperativa mostrou possuir uma infra-estrutura melhor e um pessoal mais bem treinado que os demais açougues envolvidos no le-

vantamento. As vacas que participaram do levantamento deveriam obrigatoriamente pertencer a um dos três escores de condição corporal determinados como mais freqüentes na primeira fase do período de coleta dos dados. Essas vacas foram ainda agrupadas em três grupos genéticos: azebuadas, holandesadas e mestiças.

A determinação da condição corporal (CC) das vacas foi realizada por visualização, seguindo tabela de Richards et al. (1986). Essa avaliação era feita sempre antes do abate das vacas, dispensando-se maior atenção a alguns pontos anatômicos. Os animais recebiam uma nota pelo $1^{\mathrm{o}}$ avaliador e, em seguida, eram fotografados para posterior avaliação por mais dois avaliadores (seguindo os mesmos critérios), sendo as notas dos três avaliadores completamente independentes. Além da foto, era feita uma ficha (individual) de identificação em que constavam dados, tais como: pelagem, tipo racial, peso vivo, escore de condição corporal (nota do $1^{\underline{0}}$ avaliador) e número de controle. As notas dos três avaliadores eram somadas e era tirada uma média que correspondia ao escore de condição corporal que se encontrava o animal analisado. As vacas eram pesadas, individualmente, logo após desembarcarem no matadouro; o animal era identificado (por meio de ficha e fotografia) e o peso, anotado. Logo após o abate, depois de retirada a gordura renal e pélvica, as meias carcaças eram pesadas, antes de entrarem para a câmara de resfriamento. Nesse momento, as meias carcaças eram identificadas com etiqueta plástica (com dados de identificação: $\mathrm{n}^{\mathrm{o}}$ de con-

Ciênc. agrotec., Lavras, v. 28, n. 3, p. 637-646, maio/jun., 2004 
trole individual, açougue, data, etc), a qual era amarrada no braço (região do úmero). Essa etiqueta permanecia em cada meia carcaça até essas irem para Casa de Carnes Ipê, onde eram pesados os cortes do traseiro especial. Os rins eram retirados de cada meia carcaça e a gordura que se depositava ao redor e na cavidade pélvica era pesada e os pesos, anotados. O rendimento de carcaça quente foi calculado pela relação entre o peso da carcaça quente e o peso vivo tomado antes do abate.

Após o resfriamento das carcaças em câmara fria por 12 horas, a uma temperatura média de $1^{\circ} \mathrm{C}$, foram efetuadas as medições na meia carcaça direita, seguindo escalas de valores propostas por Müller (1980). O músculo Longissimus dorsi foi exposto por um corte transversal na meia carcaça direita entre a décima segunda e décima terceira costela. Seu contorno foi traçado em papel vegetal, sendo a área obtida posteriormente, utilizando-se um planímetro. Determinou-se a espessura da camada de gordura de cobertura após exposição do músculo Longissimus dorsi (entre a $12^{\mathrm{a}}$ e $13^{\mathrm{a}}$ costela); a medida foi efetuada nessa mesma peça em um ponto situado a $3 / 4$ de distância da porção distal desse músculo, com uso de um paquímetro. $\mathrm{Na} \mathrm{Ca}$ sa de Carnes Ipê da Cooperativa Alto Rio Grande Ltda, com as meias carcaças identificadas, após a desossa (seguindo o procedimento-padrão do estabelecimento), foram obtidos e pesados os cortes contrafilé, alcatra completa (miolo da alcatra, picanha e maminha) e filé mignon (pesado junto com a aba do filé), em balança marca Filizola, sempre pela mesma pessoa. Foram obtidas as estatísticas descritivas relacionadas aos dados das diversas variáveis. Para os dados referentes a rendimento de carcaça quente (RCQ), gordura renal e pélvica (GRP), área de olho de lombo (AOL), espessura de gordura de cobertura (EGC) e pesos dos cortes (alcatra completa, contrafilé e filé mignon), foi realizada análise estatística mediante a técnica de análise de variância, com análises em separado em função de escore de condição corporal (ECC), ou seja, efeito do escore sobre cada um dos grupos genéticos: azebuada (AZ), holandesada (HOL) e mestiça (ME), e em função do grupo genético - efeito do grupo genético em cada escore estudado: ECC 3, ECC 4 e ECC 5.

O delineamento experimental usado foi o inteiramente casualizado, com três tratamentos tanto para escore de condição corporal como para grupo genético e número de repetições diferentes (desba- lanceados), como é apresentado: para RCQ e GRP, ao se analisar o efeito do escore, o número de unidades experimentais (representado por uma vaca) por tratamentos foi: azebuadas (ECC $3=7$, ECC 4 $=15$ e ECC $5=18)$; holandesadas $(\operatorname{ECC~} 3=19$, ECC $4=14$ e ECC $5=06)$ e mestiças $($ ECC3 $=16$, ECC $4=30$ e ECC 5=15). Ao se verificar o efeito dos grupos genéticos em cada escore, o número de repetições foi: $\mathrm{ECC} 3(\mathrm{AZ}=07, \mathrm{HOL}=19$ e $\mathrm{ME}=$ 16); $\mathrm{ECC} 4(\mathrm{AZ}=15, \mathrm{HOL}=14$ e $\mathrm{ME}=30)$ e $\mathrm{ECC}$ $5(\mathrm{AZ}=18, \mathrm{HOL}=06$ e $\mathrm{ME}=15)$. Para as variáveis AOL e EGC, as repetições de cada tratamento foram: efeito do escore: azebuada $(05,05$ e 08); holandesada $(13,11$ e 06$)$ e mestiça $(10,16$ e 05$)$, para os escores 3, 4 e 5, respectivamente; efeito do grupo genético: ECC $3(05,13$ e 10); ECC 4 (05, 11 e 16) e ECC 5 (08, 06 e 05) para azebuada, holandesada e mestiça, respectivamente.

Para a variável peso dos cortes (alcatra completa, contrafilé e filé mignon), as repetições foram: efeito do escore: azebuada $(04,04$ e 05$)$; holandesada $(11,05$ e 04$)$ e mestiça $(06,09$ e 06$)$ para os escores 3,4 e 5 , respectivamente; efeito do grupo genético: ECC $3(04,11$ e 06); ECC 4 (04, 05 e 09$)$ e ECC $5(05,04$ e 06) para azebuada, holandesada e mestiça, respectivamente.

Foram realizadas análises de variância, e quando o valor de $\mathrm{F}$ foi significativo, as médias dos tratamentos foram comparadas pelo teste de Tukey.

\section{RESULTADOS E DISCUSSÃO}

A avaliação da condição corporal (CC) de todas as vacas abatidas na FASE -1, apresentada na Figura 1, mostra a ocorrência de vacas com escore de 2 a 6; percebe-se que, em relação ao ECC, a distribuição é ligeiramente assimétrica, com maior freqüência de animais no escore 4, considerado como intermediário por Richards et al. (1986). Na Figura 1 verificase a freqüência de cada escore de condição corporal, podendo-se observar uma maior proporção de vacas com CC igual a 3, 4 e 5, classificadas de magra para moderadamente gordas na escala de Richards et al. (1986). Essa porcentagem mais alta de vacas com acabamento inadequado pode ser reflexo da origem leiteira das fêmeas que, em geral, são descartadas sem passar por um período de preparação para a venda, ressaltando-se mais uma vez a necessidade de utilização de estratégias, pelo produtor, por ocasião do descarte desses animais. Resultado semelhante foi obser- 
vado durante os levantamentos realizados pela indústria da carne americana: Na NNFBQA (1994), 22,4\% das vacas de corte e 19,3\% das vacas leiteiras apresentaram escore de condição corporal considerado moderado (igual a 5), enquanto na NMCBBQA (1999), essa porcentagem foi mais alta ainda, ou seja, $30,7 \%$ para as vacas de corte e $25,2 \%$ para as leiteiras, com $72,3 \%$ das carcaças classificadas com escore de musculosidade 1 ou 2, demonstrando o elevado número de vacas com acabamento inferior. No trabalho de Apple et al. (1999), carcaças de vacas condicionadas com escores 2 e 3 foram classificadas como inferiores e a carne foi destinada à produção de carne moída.

A FASE - 2 do levantamento teve a participação apenas de vacas com escore de condição corporal 3,4 ou 5, determinados como mais freqüentes na FASE - 1. Foram avaliadas 140 fêmeas, das quais 42 , 59 e 39 vacas apresentavam, respectivamente, escore corporal 3, 4 e 5, como é visualizada na Tabela 1 .
TABELA 1 - Freqüência absoluta e relativa do número de fêmeas em cada escore de condição corporal.

\begin{tabular}{ccc}
\hline ECC & $\begin{array}{c}\text { Freqüiência } \\
\text { absoluta }\end{array}$ & $\begin{array}{c}\text { Freqüência rela- } \\
\text { tiva (\%) }\end{array}$ \\
\hline 3 & 42 & 30 \\
4 & 59 & 42 \\
\hline 5 & 39 & 28 \\
\hline Total & 140,0 & 100,0 \\
\hline
\end{tabular}

\section{ECC - Escore de condição corporal.}

Fase 2 (15 de abril a 15 de julho de 2001).

As vacas de cada um dos três escores foram avaliadas e separadas por grupos genéticos assim classificados: azebuadas, holandesadas e mestiças; a quantidade de animais em cada um dos grupos genéticos pode ser visualizada na Tabela 2. Observou-se, também, efeito significativo $(\mathrm{P}=0,005)$, quando se realizou o teste de Qui-quadrado para cada escore de condição corporal segundo o grupo genético (Tabela 2).

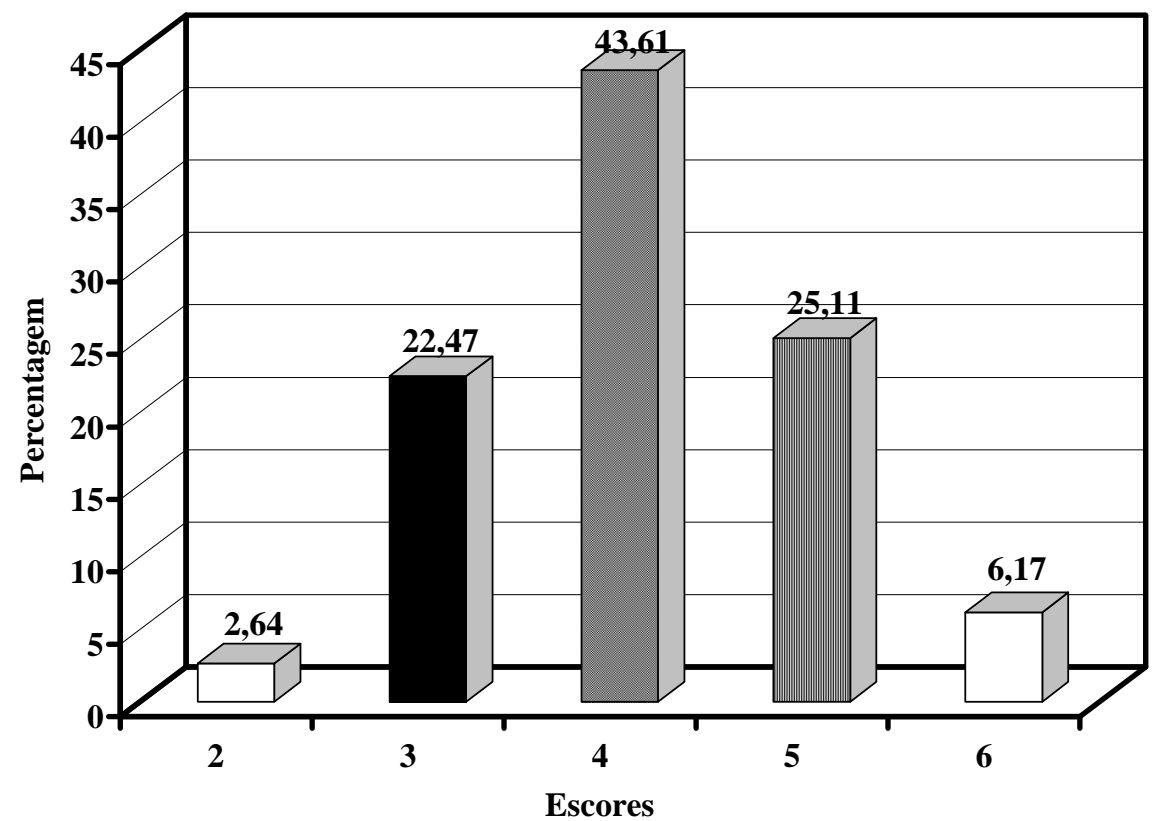

FIGURA 1 - Distribuição de freqüência relativa da condição corporal das vacas abatidas na fase 1 ( $1^{\circ}$ a 31 de março de 2001). 
Pode-se observar, na Tabela 2 , uma proporção mais equilibrada de vacas mestiças nos três escores de condição corporal; as vacas holandesadas aparecem em maior número nos escores de condições corporais mais inferiores ( 3 e 4 ), provavelmente por serem animais mais especializados para produção de leite; quando muito exigidos, perdem condição corporal, especialmente por ocasião do descarte, quando, na maioria dos casos, se encontram com idade avançada. Byer e Schelling (1988) explicam que animais com maior aptidão leiteira e de maior porte possuem vísceras altamente vascularizadas, depositando mais gordura abdominal que subcutânea, permitindo rápidas mobilizações de energia para atender a locais de maior taxa metabólica. Já as vacas azebuadas, por serem mais rústicas, suportam mais as adversidades, demorando mais para perder condição corporal, razão pela qual estão em maior número no escore de condição corporal 5, pois, segundo Josahkian (1999), os zebuínos suportam muito mais as condições de manejo e o ambiente da pecuária brasileira. Para Holechek et al. (1989), a maior quantidade de gordura subcu- tânea nos zebuínos poderia ser o resultado da seleção natural, que leva alguns ruminantes a armazenarem, nos períodos de abundância e de melhor qualidade dos pastos, reserva corporal para se manter nas épocas de escassez alimentar, tendo, dessa forma, maior probabilidade de sobrevivência que animais menos adaptados.

Na Tabela 3, são apresentadas as médias de peso da carcaça quente analisadas em função do escore de condição corporal e do grupo genético.

Pela análise de variância, verificou-se que as vacas holandesadas apresentaram maiores pesos $(\mathrm{P}<001)$ de carcaça quente que as vacas azebuadas e mestiças. Também foi observado efeito significativo $(\mathrm{P}<001)$ do escore de condição corporal sobre o peso da carcaça quente, com as vacas de $\mathrm{CC}$ igual a 5 apresentando as maiores médias nos três grupos genéticos (azebuadas, holandesadas e mestiças).

Os resultados referentes ao rendimento de carcaça quente em função do escore de condição corporal e do grupo genético encontram-se na Tabela 4.

TABELA 2 - Distribuição de frequiência em cada escore de condição corporal segundo o grupo genético.

\begin{tabular}{|c|c|c|c|c|c|}
\hline & \multirow{2}{*}{ Escores } & \multicolumn{3}{|c|}{ Grupo Genético } & \multirow{2}{*}{ Total } \\
\hline & & Azebuada & Holandesada & Mestiça & \\
\hline \multirow{2}{*}{3} & $\mathrm{~N}^{\mathrm{o}}$ de animais & 07 & 19 & 16 & \multirow{2}{*}{42} \\
\hline & Porcentagem & 17,50 & 48,72 & 26,23 & \\
\hline \multirow{2}{*}{4} & № de animais & 15 & 14 & 30 & \multirow{2}{*}{59} \\
\hline & Porcentagem & 37,50 & 35,90 & 49,18 & \\
\hline \multirow{2}{*}{5} & $\mathrm{~N}^{\mathrm{o}}$ de animais & 18 & 06 & 15 & \multirow{2}{*}{39} \\
\hline & Porcentagem & 45,00 & 15,38 & 24,59 & \\
\hline & Total & 40 & 39 & 61 & 140 \\
\hline
\end{tabular}

Teste de Qui-quadrado $(\mathbf{P}=\mathbf{0 , 0 0 5})$

TABELA 3 - Médias do peso de carcaça quente em quilogramas (erro padrão), em função do escore de condição corporal e do grupo genético.

\begin{tabular}{ccccc}
\hline \multirow{2}{*}{ Grupo Genético } & \multicolumn{3}{c}{ Escore de condição corporal } & \multirow{2}{*}{ Média } \\
\cline { 2 - 4 } & $\mathbf{3}$ & $\mathbf{4}$ & $\mathbf{5}$ & $195,06(5,61) \mathrm{B}$ \\
Azebuada & $156,14(12,34)$ & $191,70(8,43)$ & $213,00(7,70)$ & $218,87(5,87) \mathrm{A}$ \\
Holandesada & $202,18(7,49)$ & $226,04(8,73)$ & $255,00(13,33)$ & $197,77(4,39) \mathrm{B}$ \\
Mestiça & $173,56(8,16)$ & $202,40(5,96)$ & $214,33(8,43)$ & \\
\hline Média & $183,61(5,53) \mathrm{c}$ & $205,29(4,51) \mathrm{b}$ & $219,97(5,85) \mathrm{a}$ & \\
\hline
\end{tabular}

Médias seguidas por letras diferentes minúsculas nas linhas e maiúsculas na coluna indicam diferença significativa pelo teste de Tukey a $5 \%$ de probabilidade. 
TABELA 4 - Médias do rendimento de carcaça quente em porcentagem (desvios padrões), em função do escore de condição corporal e do grupo genético.

\begin{tabular}{cccc}
\hline \multirow{2}{*}{ Grupo Genético } & \multicolumn{3}{c}{ Escore de condição corporal } \\
\cline { 2 - 4 } & $\mathbf{3}$ & $\mathbf{4}$ & $\mathbf{5}$ \\
\hline Azebuada & $46,77(1,44) \mathrm{cA}$ & $49,30(1,51) \mathrm{bA}$ & $53,21(2,12) \mathrm{aA}$ \\
Holandesada & $43,18(0,85) \mathrm{cC}$ & $46,34(1,33) \mathrm{bC}$ & $48,52(1,30) \mathrm{aC}$ \\
Mestiça & $44,36(1,43) \mathrm{cB}$ & $47,61(1,31) \mathrm{bB}$ & $50,97(1,94) \mathrm{aB}$ \\
\hline
\end{tabular}

Médias seguidas por letras diferentes minúsculas nas linhas indicam diferença significativa entre escores pelo teste de Tukey a $5 \%$ de probabilidade dentro de cada grupo genético.

Medias seguidas por letras maiúsculas nas colunas indicam diferença entre os grupos genéticos pelo teste de Tukey a $5 \%$ de probabilidade dentro de cada escore corporal.

A análise de variância mostrou que houve efeito significativo $(\mathrm{P}<001$,$) do escore de condição corporal$ sobre o rendimento de carcaça quente (RCQ), com o maior rendimento observado entre as vacas de $\mathrm{CC}$ igual a 5, nos três grupos genéticos (azebuadas, holandesadas e mestiças). Esse resultado está de acordo com o apresentado por Apple et al. (1999), os quais compararam a influência do escore de condição corporal sobre as características de carcaça e o rendimento de cortes secundários em 83 vacas de descarte, encontrando um aumento linear no rendimento de carcaça quente: $48,7 \%$ em vacas de CC igual a 2 e $55,1 \%$ nas vacas com CC 8 .

Também foi detectada diferença estatística significativa $(\mathrm{P}<0,01)$ entre os grupos genéticos dentro de cada escore corporal (Tabela 4). O rendimento de carcaça quente foi significativamente superior para as vacas azebuadas nos três escores de condições corporais; as vacas holandesadas apresentaram o menor rendimento dos três grupos genéticos, ficando as vacas mestiças em posição intermediária (Tabela 4).

Essa superioridade no rendimento de carcaça quente das vacas zebuínas mostra concordância com dados de outros experimentos disponíveis na literatura, que compararam bovinos de raças zebuínas com taurinos e mestiços leiteiros (LORENZONI, 1984; JORGE, 1993; MOLETTA e RESTLE, 1996). Segundo Clarke e Wythes (1992) e Mclntyre (1994), raças zebuínas (tanto leiteiras como de corte) tendem a apresentar maiores rendimentos de carcaça que as taurinas, com vantagens de 2 a $4 \%$. Para Mclntyre (1994), esse maior rendimento de carcaça dos zebuí- nos pode ser atribuído ao menor peso do trato digestivo dos mesmos.

Os dados referentes à área de olho de lombo, espessura de gordura de cobertura e gordura renal e pélvica, analisados em função do escore de condição corporal (resultados nas linhas) e em função do grupo genético (resultados nas colunas), estão apresentados na Tabela 5 .

Com relação à área de olho de lombo (AOL), a análise de variância em função do escore de condição corporal mostrou só ter ocorrido efeito significativo $(\mathrm{P}<0,01)$ para as vacas azebuadas, com as vacas de $\mathrm{CC}$ igual a 5 apresentando as maiores médias. Não foi detectada diferença significativa $(\mathrm{P}>0,05)$ para essa variável entre as vacas holandesadas e mestiças. No entanto, ao se analisar essa mesma característica (AOL) em função do grupo genético dentro de cada escore de condição corporal, pode-se observar (Tabela 5) efeito significativo $(\mathrm{P}<0,05)$, com as vacas holandesadas apresentando as maiores médias nos três escores avaliados neste estudo. O valor superior de AOL apresentado pelas vacas holandesadas nas três condições corporais talvez possa ser explicado pelo fato de ser a categoria que teve o maior porte, já que Luchiari Filho (2000) ressalta que animais de porte grande apresentam massa muscular e área de olho de lombo maiores que animais de menor porte; esse grupo genético também apresentou superioridade na média dos pesos da carcaça quente em relação às vacas azebuadas e mestiças, como foi mostrado na Tabela 3. 
TABELA 5 - Médias e desvios padrões da área de olho de lombo (AOL), espessura de gordura de cobertura (EGC) e peso da gordura renal e pélvica em função do escore de condição corporal e do grupo genético.

\begin{tabular}{lllll}
\hline \multirow{2}{*}{ Variável } & Grupo Genético & \multicolumn{3}{c}{ Escore de condição corporal } \\
\cline { 2 - 5 } & & $\mathbf{3}$ & $\mathbf{4}$ & $\mathbf{5}$ \\
\hline Área de olho de lombo $\left(\mathrm{cm}^{2}\right)$ & Azebuada & $49,60(1,14) \mathrm{bB}$ & $52,80(4,55) \mathrm{ab} \mathrm{AB}$ & $61,88(7,77) \mathrm{aB}$ \\
& Holandesada & $56,23(6,38) \mathrm{aA}$ & $58,36(8,62) \mathrm{aA}$ & $64,83(6,34) \mathrm{aA}$ \\
& Mestiça & $47,70(6,13) \mathrm{aB}$ & $50,75(4,01) \mathrm{aB}$ & $54,00(4,85) \mathrm{aC}$ \\
\hline & Azebuada & $1,32(0,29) \mathrm{bA}$ & $4,22(1,11) \mathrm{aA}$ & $5,46(1,72) \mathrm{aA}$ \\
Espessura de gordura de cobertura $(\mathrm{mm})$ & Holandesada & $1,24(0,40) \mathrm{bA}$ & $1,69(0,57) \mathrm{bC}$ & $2,68(0,77) \mathrm{aB}$ \\
& Mestiça & $1,04(0,20) \mathrm{bA}$ & $2,83(1,02) \mathrm{aB}$ & $3,30(1,60) \mathrm{aB}$ \\
\hline & Azebuada & $1,94(0,47) \mathrm{cA}$ & $4,23(1,20) \mathrm{bA}$ & $5,26(1,27) \mathrm{aA}$ \\
& Holandesada & $2,94(1,24) \mathrm{cA}$ & $3,94(1,12) \mathrm{bA}$ & $5,95(1,91) \mathrm{aA}$ \\
& Mestiça & $2,48(0,62) \mathrm{cA}$ & $4,10(1,31) \mathrm{bA}$ & $5,64(2,25) \mathrm{aA}$ \\
\hline
\end{tabular}

Letras minúsculas diferentes nas linhas indicam diferença significativa entre os escores pelo teste de Tukey a $5 \%$ de probabilidade dentro de cada grupo genético.

Letras maiúsculas diferentes nas colunas indicam diferença significativa $(\mathbf{P}<0,05)$ entre os grupos genéticos pelo teste de Tukey a $5 \%$ de probabilidade dentro de cada escore corporal.

Os valores obtidos para AOL em função do escore de condição corporal guardam semelhança com os dados apresentados por Apple et al. (1999), que também observaram um aumento linear dessa variável em vacas de descarte, quando houve uma elevação da condição corporal (CC); as vacas de CC igual a 2 apresentaram uma AOL de $48,7 \mathrm{~cm}^{2}$, enquanto as vacas CC 8 tiveram uma AOL de $78,4 \mathrm{~cm}^{2}$. Do mesmo modo, aumento na AOL foi observado por Schnell et al. (1997) ao ser melhorada a condição corporal de vacas de descarte que receberam dietas ricas em concentrado. Entretanto, Feijó et al. (2000), ao avaliarem vacas de descarte de dois estados corporais (magras ou médias), não encontraram diferenças significativas na AOL.

A análise de variância mostrou ter havido um efeito significativo $(\mathrm{P}<0,01)$ para a variável espessura de gordura de cobertura (EGC) em função de escore de condição corporal, com as maiores médias verificadas nas vacas de CC igual a 5, como pode ser observado no quadro de médias apresentado na Tabela 5. Ao se compararem os grupos genéticos, observa-se que só ocorreram diferenças estatísticas $(\mathrm{P}<0,01)$ entre os grupos nos escores de condições corporais 4 e 5 , com as vacas azebuadas apresentando as melhores médias (acima de 3 $\mathrm{mm})$. Ressalta-se que a gordura, além de influir no as- pecto visual da carcaça, na porção comestível e na qualidade da carne, serve também como proteção contra a desidratação durante o resfriamento da carcaça. Admitese que a espessura de gordura entre 3 e $5 \mathrm{~mm}$ garante boa proteção às carcaças resfriadas. Dessa forma, os valores encontrados para vacas azebuadas dos escores $4 \mathrm{e}$ 5 e mestiças, no escore 5, no presente estudo, podem ser considerados adequados.

O efeito significativo do escore de condição corporal sobre a EGC já era esperado, pois em diversos trabalhos (O'MARA e WILLIAMS, 1996; SCHNELL et al., 1997; APPLE et al., 1999), encontraram-se respostas de aumento linear na EGC em vacas de descarte, com a melhora na condição corporal.

A EGC mais elevada verificada neste estudo para as vacas zebuínas assemelha-se aos resultados obtidos por Perobelli et al. (1994), que também observaram superioridade das vacas zebuínas para essa variável.

Na Tabela 5, encontra-se também a média dos pesos da gordura renal e pélvica (GRP), cuja análise de variância revelou existir influência do escore de condição corporal $(\mathrm{P}<0,01)$ sobre essa variável. Resultado semelhante pode ser constatado no trabalho de Apple et al. (1999). 
Não houve diferença $(\mathrm{P}>0,05)$ entre os grupos genéticos quanto ao peso da GRP. De acordo com os dados mostrados pela literatura, esperava-se que as vacas holandesadas apresentassem as maiores médias para peso de GRP; provavelmente isso não ocorreu neste estudo pelo fato de os grupos genéticos encontrarem-se em baixa condição corporal, ou seja, as fêmeas ainda não tinham acumulado muita gordura interna. Luchiari Filho et al. (1989) encontraram maior porcentagem de GRP nos animais holandesados em trabalho no qual se compararam bovinos holandeses com bovinos de raças zebuínas.

Na Tabela 6 são apresentados os resultados da média dos pesos, em $\mathrm{kg}$, do contrafilé, da alcatra completa e do filé mignon (pesado junto com a aba), analisados em função do escore de condição corporal e do grupo genético (azebuada, holandesada e mestiça).

Para essa análise, foram utilizados os dados de apenas 54 vacas, sendo 21 pertencentes à condição corporal (CC) igual a 3; 18 vacas da CC 4 e 15 animais da CC 5.

A análise de variância para rendimento de alcatra completa em função do escore de condição corporal mostrou efeito significativo $(\mathrm{P}<0,05)$, com as vacas tanto azebuadas quanto holandesadas de $\mathrm{CC}$ igual a 5 apresentando médias de pesos superiores às vacas CC 3, não tendo as vacas de CC 4 diferido das médias das duas; para as vacas mestiças, as maiores médias foram dos animais com CC 5, as menores das vacas de $\mathrm{CC} 3$, ficando as vacas de CC 4 com as médias de peso intermediárias.

Não houve efeito significativo $(\mathrm{P}>0,05)$ do escore de condição corporal sobre o peso do contrafilé, embora as vacas holandesadas tenham apresentado médias ligeiramente superiores aos dois grupos genéticos (azebuadas e mestiças). Esperava-se que essa diferença fosse significativa, já que as mesmas apresentaram médias de área de olho de lombo estatisticamente superiores às demais.

Para o filé mignon, só ocorreu diferença estatística $(\mathrm{P}<0,05)$ sobre as médias de peso das vacas azebuadas, com as maiores médias observadas entre as vacas de CC 5, e as piores, nas vacas de CC 3; as médias das vacas de CC 4 não diferiram das outras duas.

Esses resultados assemelham-se aos encontrados por Apple et al. (1999), que observaram um aumento linear no rendimento dos cortes do traseiro entre as carcaças de vacas de CC 3, 4, 5 e 6; as vacas de CC 2, 7 e 8 apresentaram, de maneira geral, rendimentos mais baixos dos cortes; as primeiras (CC 2), pela baixa condição de musculosidade e, as vacas de CC 7 e 8 , pela maior remoção de gordura durante a desossa.

TABELA 6 - Médias e desvios padrões dos pesos, em $\mathrm{kg}$, da alcatra completa, do contrafilé e do filé mignon (com a aba do filé) das duas meias carcaças, em função da condição corporal e do grupo genético.

\begin{tabular}{llccr}
\hline \multirow{2}{*}{ Variável } & Grupo Genético & \multicolumn{3}{c}{ Escore de condição corporal } \\
\cline { 3 - 5 } & & $\mathbf{3}$ & $\mathbf{4}$ & $\mathbf{5}$ \\
\hline \multirow{2}{*}{ Alcatra completa $(\mathrm{kg})$} & Azebuada & $10,28(0,68) \mathrm{bA}$ & $11,40(1,60) \mathrm{abA}$ & $13,18(1,50) \mathrm{aA}$ \\
& Holandesada & $10,20(1,20) \mathrm{bA}$ & $11,38(1,69) \mathrm{abA}$ & $12,18(1,36) \mathrm{aA}$ \\
& Mestiça & $10,43(0,42) \mathrm{cA}$ & $11,57(1,16) \mathrm{bA}$ & $13,07(0,97) \mathrm{aA}$ \\
\hline \multirow{2}{*}{ Contra filé $(\mathrm{kg})$} & Azebuada & $9,20(0,18) \mathrm{aA}$ & $10,58(1,70) \mathrm{aA}$ & $12,05(1,94) \mathrm{aA}$ \\
& Holandesada & $10,36(1,39) \mathrm{aA}$ & $10,60(1,94) \mathrm{aA}$ & $12,73(1,49) \mathrm{aA}$ \\
& Mestiça & $9,57(0,35) \mathrm{aA}$ & $10,44(1,94) \mathrm{aA}$ & $11,58(1,78) \mathrm{aA}$ \\
\hline \multirow{2}{*}{ Filé Mignon $(\mathrm{com}$ a aba) $(\mathrm{kg})$} & Holandesada & $4,03(0,17) \mathrm{bA}$ & $4,51(0,31) \mathrm{abA}$ & $4,75(0,47) \mathrm{aA}$ \\
& Mestiça & $4,44(0,73) \mathrm{aA}$ & $4,51(0,24) \mathrm{aA}$ & $5,13(0,28) \mathrm{aA}$ \\
& & $4,08(0,55) \mathrm{aA}$ & $4,22(0,31) \mathrm{aA}$ & $4,68(0,52) \mathrm{aA}$ \\
\hline
\end{tabular}

Médias seguidas por letras minúsculas diferentes nas linhas indicam diferença significativa entre os escores pelo teste de Tukey a $5 \%$ de probabilidade dentro de cada grupo genético.

Médias seguidas por letras maiúsculas difarentes nas colunas indicam diferença significativa entre os grupos genéticos pelo teste de Tukey a $5 \%$ de probabilidade dentro de cada escore corporal. 
Não foram observadas diferenças estatísticas $(\mathrm{P}>0,05)$ entre os grupos genéticos, para os pesos de nenhum dos cortes (alcatra, contrafilé e filé), em todos os três escores de condição corporal avaliados neste estudo. Berg e Butterfield (1976), com base na dissecação de carcaças, demonstraram que a distribuição do peso de diferentes músculos não varia entre as raças taurinas de leite e corte.

\section{CONCLUSÕES}

Conclui-se que as vacas abatidas no município de Lavras - MG, entre os meses de março a julho, apresentaram baixa condição corporal; a condição corporal de vacas de descarte por ocasião do abate tem influência sobre as características de rendimento na carcaça, e as vacas holandesadas, mais que os outros dois grupos genéticos, necessitam de estratégias que possam melhorar a condição corporal delas antes do descarte, aumentando, assim, a qualidade da carne e a rentabilidade para o produtor.

\section{REFERÊNCIAS BIBLIOGRÁFICAS}

APPLE, J. K.; DAVIS, J. C.; STEPHENSEON, J.; HANKIS, J. E.; DAVIS, J. R.; BEATY, S. L. Influence of body condition score on carcass characteristics and subprimal yield from cull beef cows. Journal of Animal Science, Champaign, v. 77, n. 10, p. 2660 2669, Oct. 1999.

BERG, R. T.; BUTTERFIELD, R. M. New concepts of cattle growth. New York: Sydney University, 1976. 240 p.

BYER, F. M.; SCHELLING, G. T. Nutrition in growth. In: CHURCH, D. C. (Ed.). The ruminant animal: digestive physiology and nutrition. New Jersey: Prentice Hall, 1988. p. 503-512.

CLARKE, M. R.; WYTHES, J. R. A comparison of zebu cross and shorthorn steers grown in the channel country of southwest Queensland. Proceedings Australian Society Animal Production, Brisbane, v. 19, p. 78-80, 1992.

FEIJÓ, B. L. D.; SILVA, J. M.; THIAGO, L. R. L. S.; JOBA, I.; SILVA, R. L. Produção e qualidade da carne de vacas de descarte: características das carcaças de vacas em confinamento sob diferentes níveis de concentrado. In: REUNIÃO DA SOCIEDADE BRASILEIRA DE ZOOTECNIA, 37., 2000, Viçosa, MG. Anais... Viçosa: SBZ, 2000. p. 476.
HOLECHEK, J. L.; PIEPER, R. D.; HERBER, C. H. Range management: principles and practices. New Jersey: Prentice Hall, 1989. 501 p.

JORGE, A. M. Ganho de peso, conversão alimentar e características da carcaça de bovinos e bubalinos. 1993. Dissertação (Mestrado em Zootecnia) - Universidade Federal de Viçosa, Viçosa, 1993.

JOSAHKIAN, L. Conformação é a maior pontuação. Revista Nelore, São Paulo, n. 61, p. 17, 1999. Edição especial.

LORENZONI, W. R. Estudos sobre a eficiência nutritiva e qualidade da carcaça de diversos grupos genéticos de bovinos. 1984. 51 f. Dissertação (Mestrado em Zootecnia) - Universidade Federal de Viçosa, Viçosa, 1984.

LUCHIARI FILHO, A. Pecuária da carne bovina. São Paulo: [s.n.], 2000. 134 p.

LUCHIARI FILHO, A.; LEME, P. R.; RAZOOK, A. G.; NARDON, R. F.; OLIVEIRA, W. de J. Características de carcaça e rendimento da porção comestível de machos Nelore comparados a cruzados F1 obtidos do acasalamento de touros das raças Canchim, Santa Gertrudis, Caracu, Holandês e Suíço com fêmeas Nelore II: animais castrados terminados a pasto. Boletim da Indústria Animal, Nova Odessa, v. 46, n. 1, p. 27-35, jan./jun. 1989.

McLNTYRE, B. L. Differences in dressing percent between Brahman cross and Angus cattle raised on pasture. Proceedings of the Australian Society Animal Production, Brisbane, v. 20, p. 354, 1994.

MOLETTA, J. L.; RESTLE, J. Características de carcaça de novilhos de diferentes grupos genéticos terminados em confinamento. Revista da Sociedade Brasileira de Zootecnia, Viçosa, v. 25, n. 5, p. 876-888, set./out. 1996.

MÜLLER, L. Normas para avaliação de carcaças e concurso de carcaças de novilhos. Santa Maria: [s.n.], $1980.31 \mathrm{p}$.

NATIONAL MARKET COW AND BULL BEEF QUALTY AUDIT. A survey of producerrelated defects in market cows and bulls. Englewood: National Cattlemen's Beef Association, 1999. 
NATIONAL NON-FED BEEF QUALITY AUDITY. Strategy workshop: industry information program. Denver: National Cattlemen's Association, 1994.

O'MARA, F. M.; WILLIAMS, S. E. Classification of slaughter cows and their carcasses according to carcass yield differences. In: UNITED STATE DEPARTMENT OF AGRICULTURE. Final report: development of a scientific data-base for possible use in revising present U. S. standards for grades of mature slaughter cows and their carcasses. Washington: Agricultural Marketing Service, 1996. p. 60.

PEROBELLI, Z. V.; MULLER, L.; RESTLE, J. Estudo da qualidade das carcaças e da carne de vacas de descar- te de dois grupos genéticos. Ciência Rural, Santa Maria, v. 24, n. 3, p. 613-616, set./dez. 1994.

RICHARDS, M. W.; SPTIZER, J. C.; WARNER, M. B. Effect of varying levels of postpartum nutrition and body condition at calving on subsequent reproductive performance in beef cattle. Journal of Animal Science, Champaign, v. 62, n. 2, p. 300-306, Feb. 1986.

SCHNELL, T. D.; BELK, K. E.; TATUM, J. D.; MILLER, R. K.; SMITH, G. C. Performance, carcass and palatability traits for cull cows fed with high-energy concentrate diets for $0,14,28,42$ or 56 days. Journal of Animal Science, Champaign, v. 75, n. 5, p. 11951202, May 1997. 